\title{
Complex extensive urethral diverticulum on pelvic floor ultrasound and MRI
}

\author{
Victoria Asfour $^{1,2}$ (D) Vik Khullar ${ }^{2} \cdot$ Giuseppe Alessandro Digesu $^{2}$ \\ Received: 29 February 2020 / Accepted: 20 May 2020 / Published online: 13 June 2020 \\ (C) The Author(s) 2020
}

Keywords Urethral diverticulum $\cdot$ Stress incontinence $\cdot$ MRI $\cdot$ Pelvic floor ultrasound $\cdot$ Pain $\cdot$ Voiding dysfunction

\section{Introduction}

A urethral diverticulum most commonly presents with recurrent urinary tract infection (51\%), stress incontinence (45.5\%), a vaginal lump (45\%), urethral discharge (21\%), and "the 3Ds" (dysuria, dyspareunia, post-void dribbling; 9\%) [1]. Diverticula are on average $26 \mathrm{~mm}$ in diameter (range $8-45 \mathrm{~mm}$ ) [1], and are U-shaped or circumferential in $84 \%$ [1].

\section{Case study}

A 49-year-old patient presented with a 4-year history of severe urgency, frequency every $30 \mathrm{~min}$, nocturia, but not incontinence. She described an almost continuous urgency (and sometimes pain) that did not get relieved with micturition. She experienced dyspareunia, dysuria and voiding dysfunction.

This was a tertiary level referral, as the patient had not experienced any improvement from assessment and management in other units for the last 2 years. At the time of referral, she had received first- and second-line medical treatments for overactive bladder and bladder installations. She had been previously investigated with urodynamics and cystoscopy. When she attended video urodynamics (VCU), she was tearful about the prospect of being catheterised, as this was always very painful. At this point, she was offered a pelvic floor ultrasound scan instead. The pelvic floor scan revealed an extensive cystic structure around the urethra (Fig. 1). MRI confirmed a urethral diverticulum in an extensive and unusual configuration, consistent with the pelvic floor ultrasound findings (Figs. 2, 3). Cystoscopy confirmed the opening to be at 7 o'clock at the mid-portion of the urethra.

The multidisciplinary urogynaecology team suggested resection of the urethral diverticulum with a Martius fat pad flap, to reduce the risk of post-operative stress incontinence. The patient opted for conservative management, because she was worried about the potential risk of stress incontinence post-operatively.
Victoria Asfour

Va1416@ic.ac.uk

Kingston Hospital NHS Foundation Trust, Galsworthy Road, Kingston upon Thames KT2 7QB, UK

2 St Mary's hospital, Imperial College Healthcare NHS Trust, London W2 1NY, UK 


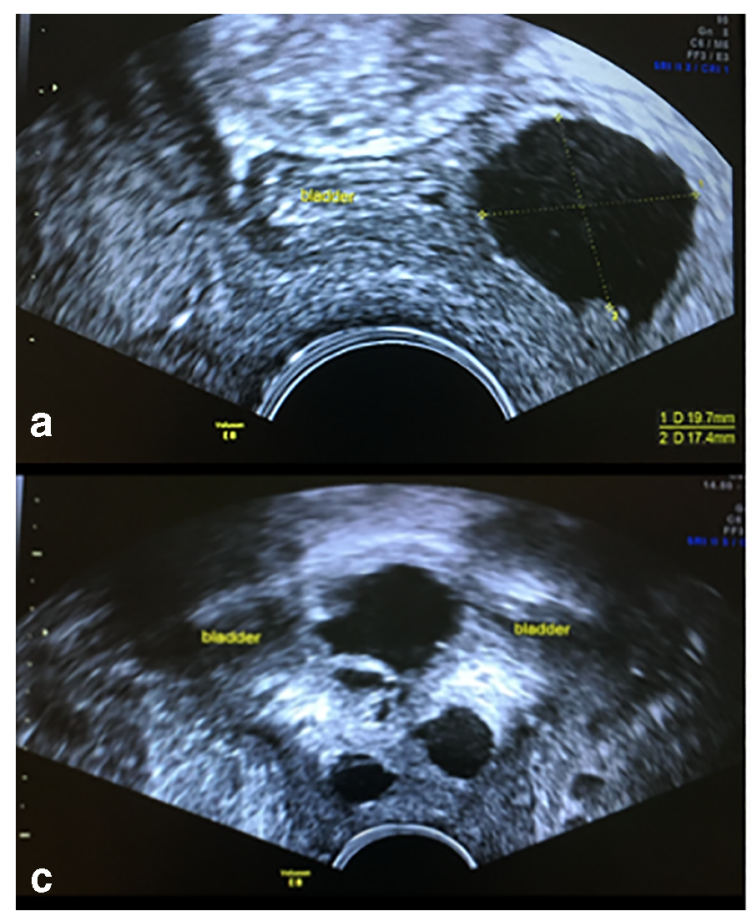

Fig. 1 Transvaginal ultrasound showing cystic lesions (diverticulum) in the bladder wall and around the urethra. a Mid-sagittal image shows a cystic portion of the diverticulum in the bladder wall over the trigone. $\mathbf{b}$ Smaller cystic lesions inferior to the larger cystic structure are shown at

\section{Discussion}

Stress incontinence may occur post-operatively, as urinary continence is a complex system that requires anatomical architecture of the urethral muscles, surrounding connec-

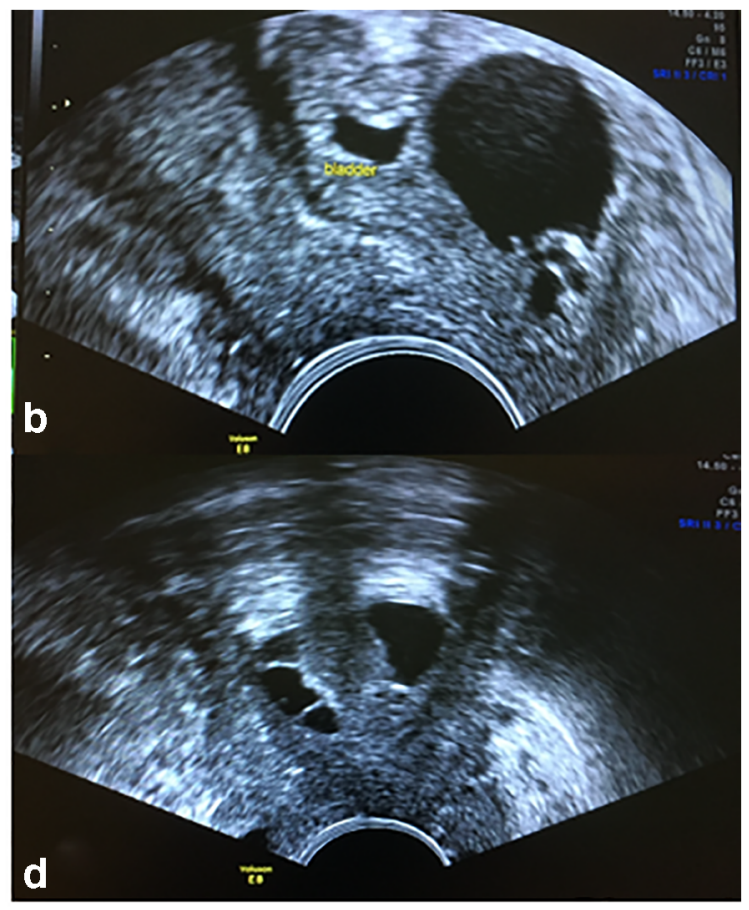

the trigone. c Coronal images show multiple cystic lesions at the base of the bladder and along the proximal urethral length. The bladder is empty. d Coronal section showing cystic structures in the distal urethra

tive tissxues and neural feedback mechanisms [2]. A series of 100 diverticula managed with excision and a Martius flap, showed resolution of pre-existing stress incontinence in $59 \%$ and de novo stress incontinence in $14 \%$ [3].

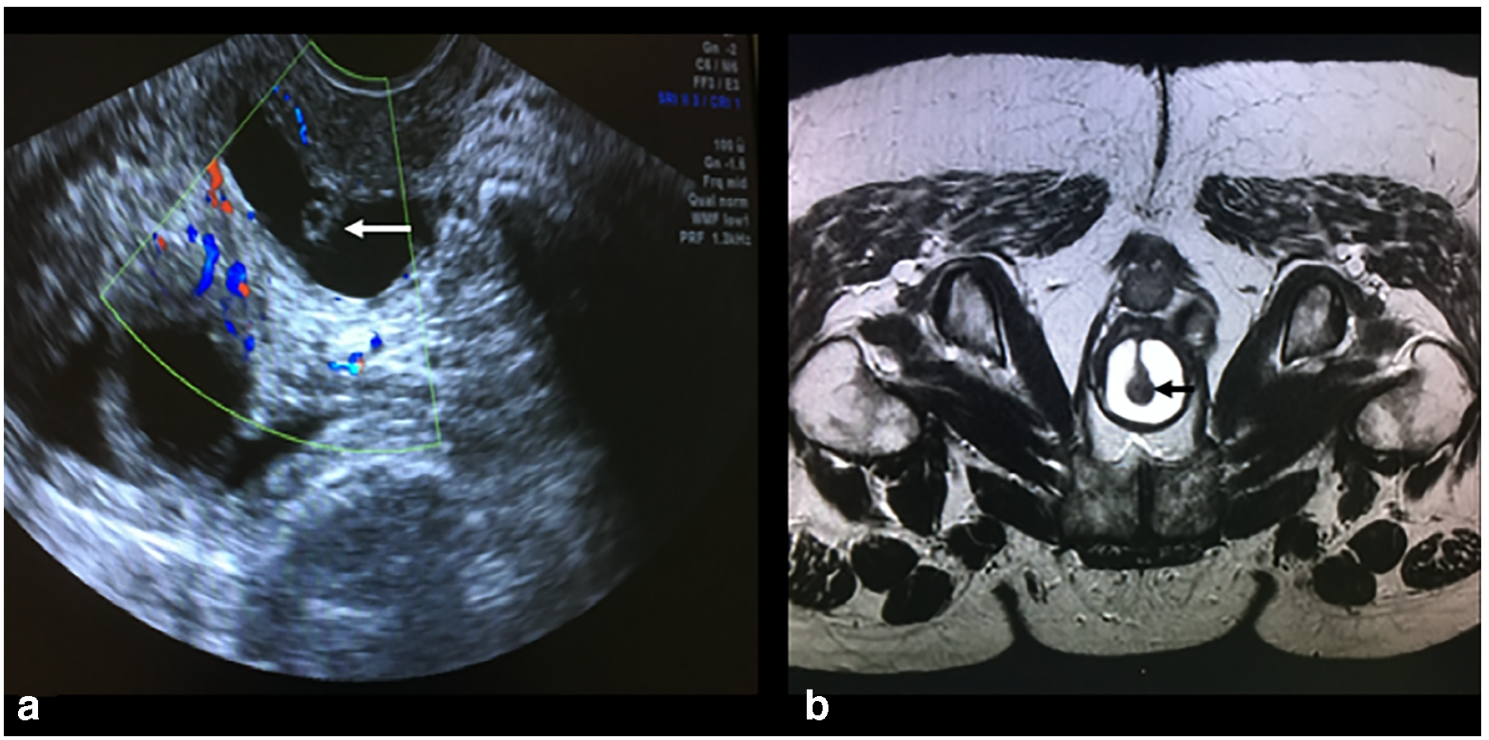

Fig. 2 a Transvaginal ultrasound showing the urethra surrounded by the diverticulum. b MRI showing the same part of the urethra. The arrows demonstrate the urethra suspended within the diverticulum 


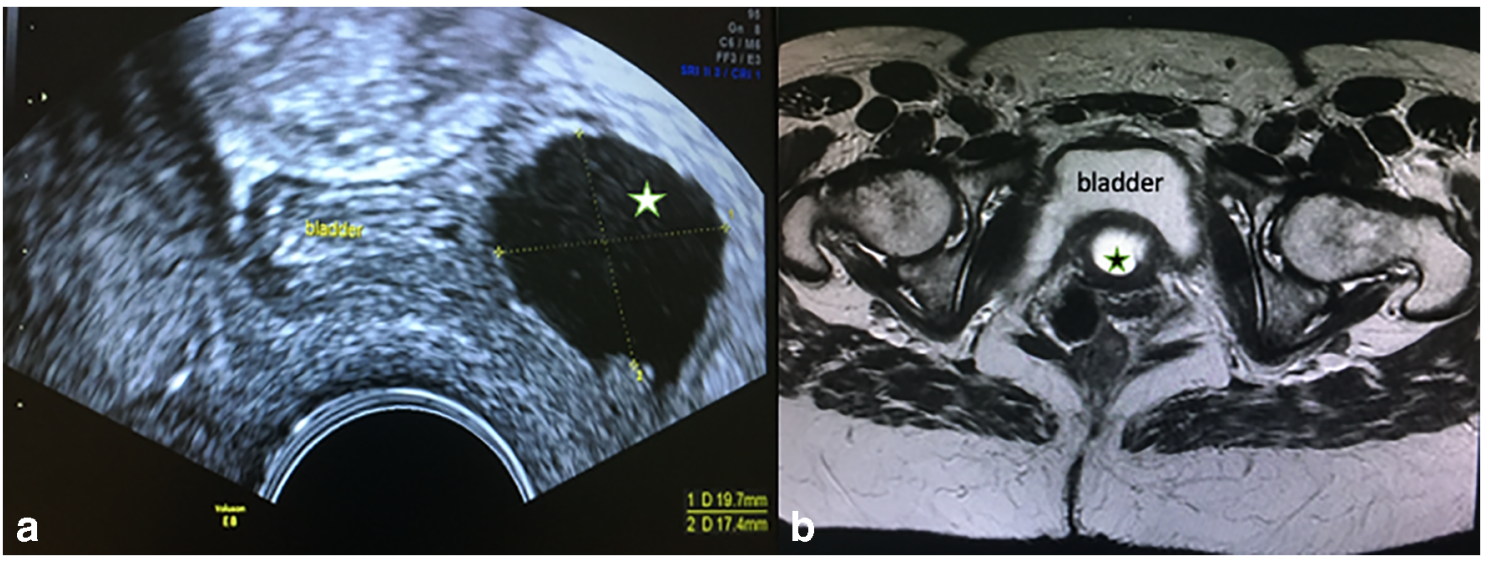

Fig. 3 Magnetic resonance image at the level of the bladder above the urethra. The star demonstrates the fluid of the diverticulum

Authors' participation V. Asfour: ultrasound scan, manuscript writing; V. Khullar: scanning, clinical care, manuscript review; G.A. Digesu: clinical care, manuscript review, idea of paper.

\section{Compliance with ethical standards}

\section{Conflicts of interest None.}

Consent Written informed consent was obtained from the patient for publication of this Images in Urogynecology article and any accompanying images.

Open Access This article is licensed under a Creative Commons Attribution 4.0 International License, which permits use, sharing, adaptation, distribution and reproduction in any medium or format, as long as you give appropriate credit to the original author(s) and the source, provide a link to the Creative Commons licence, and indicate if changes were made. The images or other third party material in this article are included in the article's Creative Commons licence, unless indicated otherwise in a credit line to the material. If material is not included in the article's Creative Commons licence and your intended use is not permitted by statutory regulation or exceeds the permitted use, you will need to obtain permission directly from the copyright holder. To view a copy of this licence, visit http://creativecommons.org/licenses/by/4.0/.

\section{References}

1. Liu D, Qing Z, Wen L. The use of tomographic ultrasound imaging on three-dimensional translabial ultrasound: a diagnostic sign for urethral diverticulum. Int Urogynecol J. 2019. https://doi.org/10. 1007/s00192-019-04111-8.

2. Mistry MA, Klarskov N, DeLancey JO, Lose G. A structured review on the female urethral anatomy and innervation with an emphasis on the role of the urethral longitudinal smooth muscle. Int Urogynecol J. 2020;31(1):63-71.

3. Barratt R, Malde S, Pakzad M, Hamid R, Ockrim J, Greenwell T. The incidence and outcomes of urodynamic stress urinary incontinence in female patients with urethral diverticulum. Neurourol Urodyn. 2019;38(7):1889-900.

Consent Written informed consent was obtained from the patient for publication of this case report and any accompanying images.

Publisher's note Springer Nature remains neutral with regard to jurisdictional claims in published maps and institutional affiliations. 